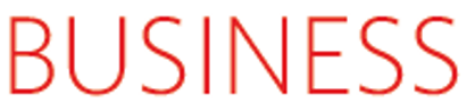

\title{
Make or break time in Vioxx drama
}

\section{Cases involving long-term users of Vioxx will, as Meredith Wadman reports, determine the true cost to Merck and the drug industry of the painkiller's withdrawal.}

In a trial that opened on 6 March in Atlantic City, New Jersey, lawyers led by a charismatic Texan are trying to convince a jury that Merck's blockbuster painkiller caused heart attacks in two allegedly long-term users.

It is the first time that the company has confronted plaintiffs who have taken the drug for more than 18 months - the period after which, according to the study that led Merck to pull the drug in September 2004, Vioxx boosts the risk of heart attacks and strokes.

That makes the stakes in the current trial arguably the highest yet. "A win for Merck may deflate the entire plaintiff case," says Anthony Butler, an analyst who is following the litigation for the investment bank Lehman Brothers in New York.

The withdrawal of Vioxx, a leading arthritis treatment that earned Merck $\$ 2.5$ billion in 2003 , has so far led to nearly 10,000 lawsuits against the company. In the first of those, last summer, a jury in the Texas town of Angleton awarded $\$ 253$ million to the widow of a man who had a fatal heart attack after taking Vioxx for eight months (see Nature 436, 1070; 2005). The award is likely to be cut to $\$ 26.1$ million under a Texas law capping punitive damages.

But Merck bounced back, winning the second and third cases. The second, in which a jury found that Vioxx was not responsible for the heart attack of a 60 -year-old postal worker who took the drug intermittently for two months, was heard in the same New Jersey state court as the current cases. In the third, a jury in a federal court in New Orleans last month took just three hours to dear Merck of responsibility for the death of a Florida man who suffered a fatal heart attack after taking Vioxx for less than a month.

These verdicts have helped Merck to recover a half of the steep drop in its share price that accompanied Vioxx's withdrawal (see graph). In combination with the performance of other parts of its business, some observers can see light at the end of the tunnel for the beleaguered drug maker. "At the end of the day you need to separate Vioxx from the fundamentals of the company," says Butler. "It's about the ability to pay dividends, the ability to fund your R\&D and to fund your new launches. And Merck seems to be funding its programmes regardless of the outcome of this case in Atlantic City or any in the future."

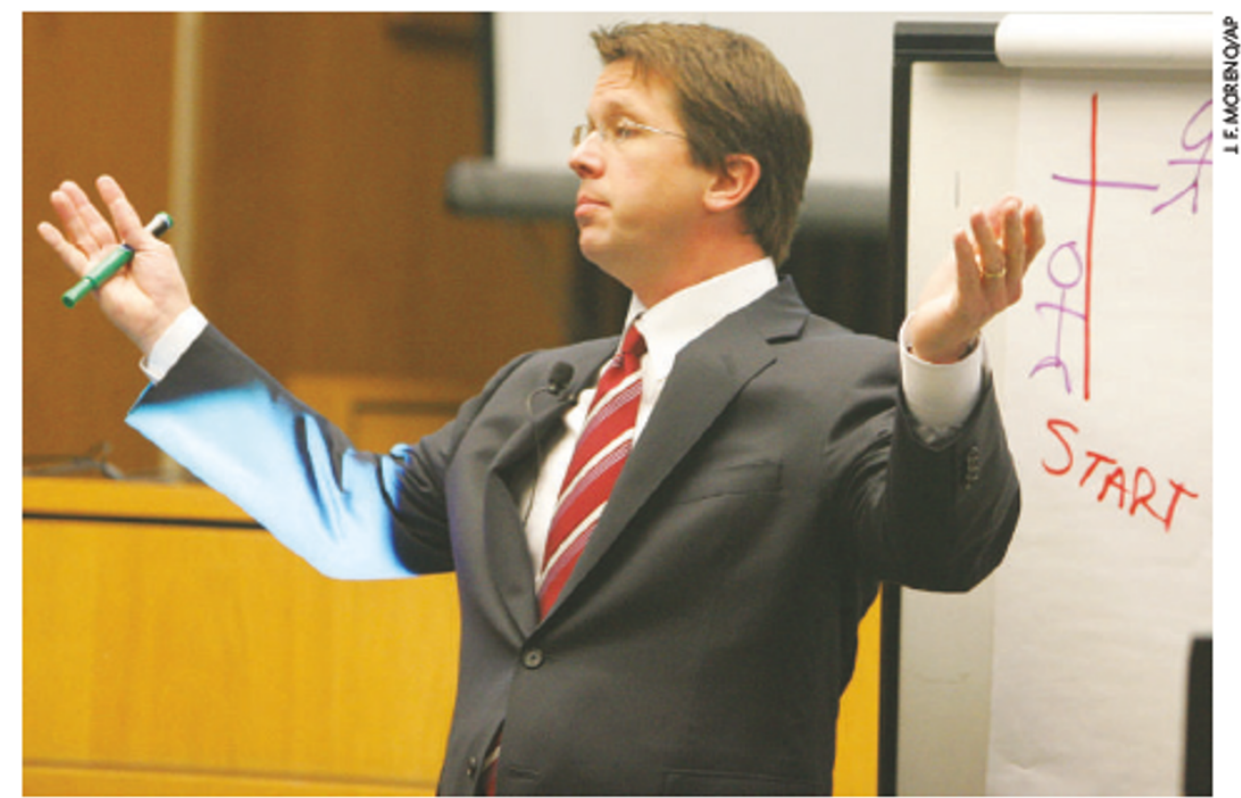

Away match: Mark Lanier hopes to repeat his Texanvictory over Merck in the company's home state.

Others are less sanguine. Late last month, the Arlington, Virginia, stock-research company Friedman Billings Ramsey lowered its rating of Merck's stock, citing Vioxx litigation risk among its reasons.

\section{Moving targets}

Published estimates of the company's probable total liability vary wildly, from $\$ 4$ billion to $\$ 50$ billion. This uncertainty is reflected in Merck's share price, says Richard Evans, an analyst who follows Merck for Sanford Bernstein, a stockresearch firm in New York. "Merck's ultimate liability remains very hard to pin down," he says. In the latest trial, sometime Baptist preacher Mark Lanier, the folksy Houston lawyer who won the Texas award last year, is representing Thomas Cona, the owner of a vascular

\section{MERCK STOCK}

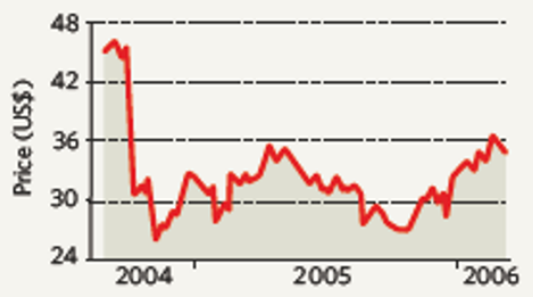

ultrasound company, who was 57 when he had a heart attack after taking Vioxx for, he says, 22 months.

But Lanier is in Merck's home state this time. And both Cona and the other plaintiff, retired insurance agent John McDarby, survived their heart attacks, potentially limiting jury sympathy. McDarby was 75, and had been taking Vioxx for four years when he suffered a heart attack after hip surgery. Both men were former smokers with high blood pressure, high cholesterol and other cardiac risk factors.

Lanier acknowledges Cona's poor heart health, but argues that this is precisely why he should never have been prescribed Vioxx. "Of course they were at risk," he says. "Vioxx shoves you toward a heart attack. And it is those at risk who can least afford a shove."

Whether juries will buy that argument remains to be seen. The issues will broaden out in June, when an Alabama court hears the first case concerning Celebrex, a Pfizer painkiller from the same family as Vioxx and the only drug of its type still on the market.

In the meantime, two victories for Merck in Atlantic City could mark a turning point in the Vioxx saga. Even one loss, however, will boost the growth of a pool of plaintiffs that could ultimately number in the tens of thousands. 